\title{
The emergence of Egyptian biotechnology from generics
}

\author{
Basma Abdelgafar, Halla Thorsteinsdóttir, Uyen Quach, Peter A Singer \& Abdallah S Daar
}

E GYPT's government and society changed substantially following the 1952 military coup that ended the British-backed monarchy. A few years later, President Gamal Abdel Nasser's controversial state-led industrialization sought to step up social, economic and industrial development under the principles of 'Arab socialism'. This included expansion of the education system, the establishment of research institutes and the creation of a ministry of science. It was not until this period that Egypt's scientific research and the deliberate pursuit of science and technology began to take shape ${ }^{1}$. It has not been an easy road.

During the past half-century, Egypt has had to deal with several geopolitical conflicts and struggles with economic problems. Egyptian scientific and technology continues to be plagued by inappropriate policies ${ }^{1}$. Nevertheless, Egypt has become one of the leading Arab states in terms of science. It has both a predominantly well-educated people and scientific capabilities that have brought success in such fields as agbiotechnology. The country is making progress in developing its health biotechnology sector.

\section{The success of Egypt's health biotechnology sector}

The success of Egypt's public health system has been traditionally measured by its ability to satisfy local demands and to respond rapidly and effectively in times of crisis. For example, 2 years ago, the Egyptian authorities

were able to respond to a shortage of insulin through the rapid local development of recombinant human insulin (see Box 1). Of the estimated 5-7 million diabetics in Egypt (of a population of about 74 million), threequarters can be treated using the recombinant hormone. Before the start of local production, over $90 \%$ of the country's total insulin needs were imported from one multinational company (Novo Nordisk,

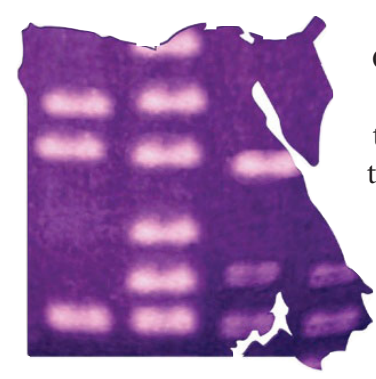
Copenhagen) at a cost of US \$35 million annually to the government ${ }^{2}$. Today, local firms have the ability to manufacture by recombinant means sufficient quantities of affordable insulin. The companies still import insulin crystals for their production but they are transitioning from importing the unfinished product for local formulation to completing the whole recombinant process in Egypt.

Egypt has had similar success in producing diagnostics and treatments for hepatitis B and C. There is a large discrepancy in available estimates of the incidence of the hepatitis $\mathrm{C}$ virus (HCV) in Egypt: the government estimates $7-8 \%$ of the population are infected ${ }^{3}$, whereas the World Health Organisation (WHO, Geneva, Switzerland) puts the figure at $15-20 \%$ (ref. 4). In any case, it is clear that the problem is serious, especially because hepatitis $\mathrm{C}$ is the fastest growing infectious disease in the country. In response, several $\mathrm{HCV}$ diagnostics have been developed for clinical use, including PCR-based kits designed to detect the HCV strains specific to the region. Researchers at the National Cancer Research Centre (Cairo) have also developed a new synthetic peptide of the core protein, which demonstrated $99 \%$ sensitivity and $100 \%$ specificity for HCV antibody in serum that could be used in large-scale population screening of HCV infection, supplementing the use of more expensive assays $^{5}$. The local production of interferon $\alpha-2 b$, a recombinant treatment for hepatitis $C$, has also provided a local substitute for expensive foreign brands that, according to one public official, were costing the government about $\$ 2,000$ annually per patient. In the area of vaccine research, a recombinant hepatitis B virus surface antigen vaccine is also being produced locally, and research is continuing to develop one for HCV.

Schistosomiasis is the leading parasitic infection in Egypt's rural population and is the number one cause of death among men aged 24-44. The Schistosomiasis Research Vaccine Development Project (Cairo; http:// www.usaid-eg.org/arabic/detail.asp?id=15) has been initiated in cooperation with US partners to help combat the disease in Egypt. The project's aim is to develop the two vaccine candidates, paramyosin and the synthetic peptide called MAP4, identified by the WHO.

Basma Abdelgafar is Assistant Professor, Department of Management, American University in Cairo, 113 Kasr El Aini Street, P.O. Box 2511, 11511 Cairo, Egypt; Halla Thorsteinsdóttir is Assistant Professor, Canadian Program on Genomics and Global Health, University of Toronto Joint Centre for Bioethics and Department of Public Health Sciences, 88 College Street, Toronto, Ontario M5G 1L4, Canada; Uyen Quach is Research Assistant, Canadian Program on Genomics and Global Health, University of Toronto Joint Centre for Bioethics, 88 College Street, Toronto, Ontario M5G 1L4, Canada; Peter A. Singer is Co-Director, Canadian Program on Genomics and Global Health and Sun Life Financial Chair, Director of University of Toronto Joint Centre for Bioethics and Professor of Medicine, University of Toronto, 88 College Street, Toronto, Ontario M5G 1L4, Canada; and Abdallah S. Daar is Director of Ethics and Policy, McLaughlin Centre for Molecular Medicine, Professor of Public Health Sciences and Surgery, University of Toronto, and Co-Director, Canadian Program on Genomics and Global Health, University of Toronto Joint Centre for Bioethics, 88 College Street, Toronto, Ontario M5G 1L4, Canada.

e-mail: halla.thorsteinsdottir@utoronto.ca 


\section{Box 1 VACSERA resolves local insulin crisis}

Late in 2002, the Egyptian government was forced to deal rapidly with what was widely perceived to be an acute insulin shortage. In cooperation with international partners from Europe and China, an emergency plan was created to permit the Vaccine and Inoculation Authority (VACSERA) to produce recombinant human insulin. Since VACSERA started production, 20 million units of insulin have been sold, and there is enough stored insulin for a 2-year supply. Local production has resulted in substantial cost savings for the government, plus independence from a long-standing foreign monopoly. For example, imports of insulin in the 40-IU form, just one part of the market, decreased from 3 million Egyptian Pounds (about US \$484,000) in 2002 to 1 million Egyptian Pounds (about US $\$ 161,000$ ) in 2003.

An important benefit of the initiative has been the impact on both VACSERA, a long established institution that has been making vaccines since the late $19^{\text {th }}$ Century, and other local pharmaceutical companies that were encouraged to play stronger roles in the health biotechnology field. VACSERA's biological products pipeline now includes recombinant human interferon $\alpha-1 b$, erythropoietin $\alpha$ and streptokinase. The company has partnered in several international agreements aimed at enhancing its scientific and technological capabilities and reach, including with developing countries such as Malaysia.

There is little doubt that Egypt's traditional pharmaceutical patent policy, with its limited scope and duration, has been instrumental in allowing local actors to adopt and adapt global health technologies. A review by the United Nations Conference on Trade and Development (UNCTAD, Geneva, Switzerland) noted: "owing to the nature of the governing patent law in Egypt (Law 132 of 1949), which allows patents to expire after 10 years, the Egyptian pharmaceutical industry has excelled in terms of manufacturing generics." ${ }^{\circ}$ Consequently, the production of generic products has traditionally accounted for a substantial portion of local industry profits, a situation that has supported the growth of the industry and encouraged rapid emergence of several suppliers of most new drugs. As a result, a whole host of 'me-too' products and biogenerics are now locally packed and/or manufactured. Table 1 presents a sample of the biotechnology products that are locally manufactured.

A comparison of Egypt's health biotechnology publications in international peerreviewed journals ${ }^{7}$ and patents granted in the United Status Patent and Trademark Office (USPTO, Washington, DC, USA; an analysis of the USPTO's database was carried out in July 2004, http://www.uspto.gov/) between 1991 and 2002 provides another view of the country's innovation level in terms of scientific output and technological activity in the field (Fig. 1). Data derived from ScienceMetrix ${ }^{7}$ shows Egypt's scientific output has been limited. Its patent activity based on inventors' addresses in USPTO-granted patents in health biotechnology (http://www. uspto.gov/) is almost nonexistent, except for the years 1999 and 2000.

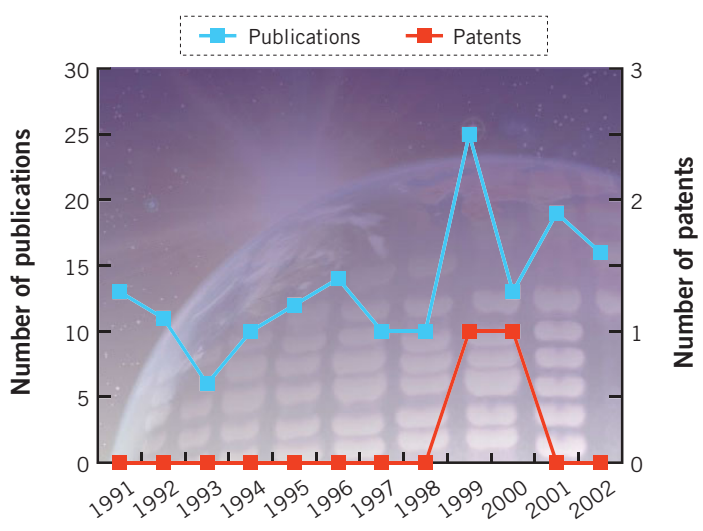

Figure 1 Egyptian publications and USPTO patents in health biotechnology (1991-2002). Source: Publication data are from ref. 7. Patent data are from the USPTO.

and skills in the sector. In the private sector, the existing base of companies manufacturing generic pharmaceuticals is also building business in recombinant products, with several firms manufacturing protein on site. These developments are generally welcomed by the population, regardless of level of education, who acknowledge that health biotechnology products offer advantages in terms reducing disease and enhancing health and wellness.

Government. Biotechnology was identified by the government as worthy of special support in the early 1980s, but it was not until a decade later that concrete measures to initiate such support were undertaken. In 1991, a focal point for genetic engineering and biotechnology was established in the Academy of Scientific Research and Technology (Cairo), a part of the Ministry of Scientific Research. A detailed strategy for the development of biotechnology and genetic engineering followed in 1995 when the then Minister of Scientific Research, Venice Kamel Gouda, personally adopted the idea. Senior policy makers were concerned about overreliance on the advanced industrial countries for the development of this sector, so they turned to local experts and to skilled expatriates from around the world to formulate a national agenda. These efforts resulted in the 'National Strategy for Genetic Engineering and Biotechnology'.

To implement this 'National Strategy', scientific committees were formed to determine appropriate policies, programs and research projects to advance biotechnology. In the area of health biotechnology, shortterm plans included the production of diagnostic kits for unspecified viral diseases, tuberculosis and schistosomiasis. They also called for the development of general product categories such as tumor marker kits, the improvement and production of vaccines for endemic diseases and the production of antibiotics. Longer term

\section{Main features of the Egyptian sector}

Although it took several years to formulate and implement a strategy, in the past 10 years the Egyptian government has been actively promoting local health care biotechnology with the aim of reducing dependence on outside producers. Funding has been channeled toward the building of new research centers and pilot manufacturing plants as well as the introduction of biotechnology educational programs at Egypt's extensive network of universities and public research institutes; even so, the country still lacks sufficient expertise plans included the production and marketing of vaccines for schistosomiasis and hepatitis $\mathrm{B}$, and the production of products under the general category of immunoregulators for the treatment of cancer and AIDS. As part of the strategy, the government allocated longterm funding to introduce biotechnology to universities and public research institutes and to establish new centers of research excellence, including three pilot plants for scaling up technology. The government also funds training and fellowships in the advanced industrial countries and has spearheaded 
several technical and trade missions around the world to facilitate exports.

On the regulatory front, the Ministry of Health has been active in facilitating drug testing, approvals, registration and pricing for products based on biotechnology. Although there have been no formal changes to the drug pricing and registration processes, informal and personal efforts have created an inviting environment for individuals and businesses to develop new technologies. An Egyptian expert interviewed for this study said, "If a company were to come to register a product that potentially had significant health or strategic outcomes, that covered a large portion of local supply or that replaced costly imports, then it would be given priority.... We remove all red tape in critical areas where we have a need." These assertions were strongly supported by other respondents, including those from industry.

Universities and public research institutes. Egypt has an extensive scientific and technological infrastructure, largely comprising 33 universities with 22 affiliated research centers, together with another 81 research centers affiliated with 16 government ministries. In response to the National Strategy, many of these institutions have established biotechnology departments, whereas others are introducing biotechnology courses and research programs. Despite these policies, there is not yet a critical mass of high-caliber professionals in designated areas, and this has slowed the development of Egypt's science and technology system. The excessive number of individuals who are not of this caliber employed in universities and public research institutes-a result of Egypt's guaranteed employment policy for outstanding new graduates-combined with budgetary and other resource constraints, has undoubtedly hindered the potential for the small number of high-caliber (usually foreign-educated) individuals.

Some exceptions do exist. Critical masses of experts have been formed in the National Research Center (Cairo), especially the Biomedical Research Department, and the

Egypt's pharmaceutical
industry is crucial for the
commercialization of the fruits
of biotechnology research,
because there are currently no
specialized biotechnology firms.

Genetic Engineering and Biotechnology Research Institute (Borg El Arab, Egypt). Thus, although much of the research undertaken within the science and technology system remains rudimentary and low-level, several scientists are involved in advanced biotechnology research, including genetic engineering and molecular biology.

Universities are the primary producers of knowledge for international peer-reviewed journals, with public research institutes gradually increasing their contribution ${ }^{7}$. Although Egypt's volume of publications is relatively modest compared with other developing countries in this study, it is important to recognize that the development of the health biotechnology sector in Egypt thus far has been based on the successful exploitation of knowledge already in the public domain more than on novel contributions by its research community.

Also noteworthy is the increasing popularity of Special Research Units (SRUs), which are located within hospitals, universities and public research institutes. These units house advanced technological equipment and teams of experts whose primary role is medical research but who also offer their services directly to the public for a fee. The main goal of the SRUs is to make better use of resources while providing critical medical services. The Medical Services Unit of the National Research Center, for instance, does molecular diagnoses and treats patients with rare dermatological and dental diseases, among others, giving the public access to the benefits of biotechnology.

Industry. Egypt's pharmaceutical industry is crucial for the commercialization of the fruits of biotechnology research, because there are currently no specialized biotechnology firms. Local pharmaceutical companies are especially strong in producing generic drugs and efficient formulations (tablets, capsules and oral solutions). Local production of pharmaceutical products satisfies $93 \%$ of domestic consumption, with imports generally limited to high-technology products such as interferon $\alpha-2 b$ and anticancer monoclonal antibodies and small molecules.

With the introduction of biotechnology, however, several local firms are breaking into this market. As with traditional generic

\begin{tabular}{|c|c|c|c|c|}
\hline Sector & Type & Product name & Application & Producer \\
\hline \multirow[t]{14}{*}{ Therapeutics } & \multirow[t]{2}{*}{ Recombinant human streptokinase } & Sedonase & \multirow[t]{2}{*}{ Cardiovascular } & $\begin{array}{l}\text { South Egypt Drug Industries Company } \\
\text { (Sedico, October City, Egypt) }\end{array}$ \\
\hline & & Streptokinase & & T3A Pharma Group (Giza, Egypt) \\
\hline & \multirow[t]{5}{*}{ Recombinant human interferon $\alpha-2 b$} & Intron A & \multirow[t]{5}{*}{ Cancer } & Medical Union Pharmaceuticals (Cairo) \\
\hline & & Reiferon & & Minapharm Pharmaceuticals (Cairo) \\
\hline & & Natuferon & & Otsuka-Egypt (Cairo) \\
\hline & & Egyferon & & El Nil Pharmaceutical (Cairo) \\
\hline & & Ismaferon & & $\begin{array}{l}\text { Alpha-Chem For Advanced Pharmaceutical } \\
\text { Industries (Cairo) }\end{array}$ \\
\hline & \multirow[t]{3}{*}{ Recombinant human erythropoietin $\alpha$} & Erypoietin & \multirow[t]{3}{*}{ Anemia } & Amoun Pharmaceutical (Cairo) \\
\hline & & Epoetin & & Sedico \\
\hline & & Pronivel & & T3A Pharma Group \\
\hline & \multirow[t]{4}{*}{ Recombinant human insulin } & Mixulin-H 30/70 & \multirow[t]{4}{*}{ Diabetes } & Amoun Pharmaceutical Co. S.A.E. \\
\hline & & Insulin $\mathrm{H}$ & & Sedico \\
\hline & & Human Insulin-Mix & & VACSERA \\
\hline & & Danofran & & T3A Pharma Group \\
\hline
\end{tabular}

aList provided by a government official dealing with drug policy and planning. 
pharmaceuticals, most companies usually import in bulk, then package the products. Some local companies, notably EIPICO (Egyptian International Pharmaceutical Industries, $10^{\text {th }}$ Ramadan City, Egypt), SEDICO (South Egypt Drug Industries Company, $6^{\text {th }}$ October City, Egypt), El Nil Pharmaceutical (Cairo) and the Vaccine and Inoculation Authority (VACSERA, Cairo), are taking the production of biotechnology products a step farther by partially or completely manufacturing them locally. Although the generic industry currently exports a mere 6\% of total domestic output (worth approximately $\$ 1.2$ billion), the industry has been identified as one of Egypt's 'rising stars' by the 1999 UNCTAD Investment Review' ${ }^{6}$.

Egypt's health biotechnology sector is not geographically clustered. Pharmaceutical firms are located in several cities and industrial zones, and research centers are found all over the country. Although Cairo can be considered the main hub of industry and research, the recent establishment of the country's first technopole (see Box 2) just outside Alexandria, in addition to several strong firms and research centers in that city, is challenging the traditional dominance of the capital.

Multinational firms generally package and/or market biotechnology products locally, with some companies, such as Eli Lilly (Indianapolis, IN) and GlaxoSmithKline (Brentford, UK), undertaking limited R\&D and clinical testing. These companies are an important source of ideas for local producers through both licensing arrangements and the importation of their biotechnology products from abroad.

The general public. Although there have been no systematic surveys of the public's acceptance or awareness of health biotechnologies in Egypt, interviewees seemed to share a similar understanding of the situation. In general, there was agreement that it is not possible to talk of 'a public' because Egyptian society is characterized by different classes and levels of education. For the middle, upper and educated classes, there is both awareness and acceptance of health biotechnologies. This includes a reasonable awareness of both benefits and risks, and an understanding or belief that the former outweigh the latter.

Those in lower socioeconomic levels were described as generally unknowledgeable or indifferent, largely because of their daily struggles to survive. In practical terms, however, this segment of society is also characterized as receptive to health biotechnologies because of an understanding that they are less costly and more effective in treating disease. Thus, as one respondent explained, even if a patient is not knowledgeable about the actual technology, it is not difficult to see the benefits from the use of a recombinant antirabies vaccine requiring only 6 shots instead of the 21 shots for a traditional form of treatment.

\section{Main challenges for development}

Like many other countries with nascent biotechnology sectors, Egypt lacks adequate funding sources to promote life science startups. With only limited government funding, no venture capital to speak of and scant interest from the banking sector, most biotechnology enterprises spring from existing companies that have an interest in recombinant technology. Another problem is the traditional focus of the country's universities on teaching and basic research, rather than applied research. These problems are compounded by poor collaboration among academic groups and centers on projects. As a

A lack of adequate funding makes it difficult to undertake long-term projects, and in some cases to complete current ones.

result, there is only a trickle of discoveries from academia to the private sector, and industry-academia collaborations are rare. The country's implementation of the Agreement on Trade-Related Aspects of Intellectual Property Rights (TRIPS) in 2005 and questions as to how the government will approach biotechnology patenting is also likely to compromise the ability of the local industry to continue to benefit and learn from biotechnologies largely developed abroad.

Limited funding. A lack of adequate funding makes it difficult to undertake long-term projects, and in some cases to complete current ones. Even the final budgetary approval of 25 million Egyptian Pounds (approximately US $\$ 4$ million) for the implementation of the National Strategy fell far short of the initial request of 160 million Egyptian Pounds (approximately US \$25.7 million). Moreover, the level of funding tends to be diluted by various systemic weaknesses that necessitate the provision of jobs and the supplementation of staff salaries with research grants.

Local banks generally have a limited role in financing the health biotechnology sector, and weak linkages between industry and academia limit crucial collaborations and financial support. Industries rely largely on existing corporate resources to undertake biotechnology projects-a situation not helped by the lack of tax or investment incentives to encourage such investments.

Overemphasis on teaching as opposed to applying science. Egypt's higher education system is greatly biased toward teaching and producing basic science rather than its applications. Of all the country's scientists and engineers, $75 \%$ are employed in the higher education sector, leaving only $25 \%$ to operate in the other sectors of the society ${ }^{8}$. This situation limits the potential contribution of Egypt's science and technology, both in terms of research outcomes and in producing qualified professionals who are capable of solving practical problems.

Addressing this issue will be very challenging without adequate funds. Although R\&D labor remains relatively inexpensive, reagents, supplies and equipment are costly, primarily because they must be imported. Moreover, basic requirements, such as purified water and sanitary conditions essential for biotechnology R\&D, are also not always available. Such conditions limit the type of research that can be done and the extent of training that can take place in universities and public research institutes.

Weak local linkages. Today, primary actors in the Egyptian health biotechnology sector describe it as one of "dispersed dynamic individuals," "isolated islands" or "successful nuclei" - an indication of the poor level of collaboration/intellectual linkages and lack of sharing of resources. Inhibiting regulations, lack of trust, the need for individual recognition and the situation of partnerships among unequals are cited as the most common obstacles to cooperation. Current government attempts to address these problems include the facilitation of local networks, the establishment of workshops to encourage relationships among key stakeholders, the founding of a coordination center and even the creation of biotechnology incubators with French and Chinese expertise.

Some of the respondents attributed the lack of collaboration to Egyptian academic culture, noting that researchers prefer to work on projects over which they have complete control and that will be clearly reflected in their career advancement. Several respondents referred to a culture of academic 'secrecy'. Research teams in different centers prefer to work independently and keep their results confidential until they are ready for release. In this way, the team avoids criticism 


\section{Box 2 MUCSAT, Egypt's first major technopole}

Located on $\mathbf{8 0}$ hectares in the Bourg El Arab Industrial Complex, just west of Alexandria, MUCSAT (Mubarak City for Scientific Research and Technology Applications) was established as a center of research excellence in advanced biotechnology with the goal of introducing valuable biotechnology products and services to the market through R\&D and technology transfer. Of the 12 institutes to be created within MUCSAT, 4 are now complete, including the Genetic Engineering and Biotechnology Research Institute.

MUCSAT boasts state-of-the-art facilities, equipment and a cadre of highly qualified personnel. According to the director of the Medical Biotechnology Department, the center is currently working on HCV diagnostics, new methods of tuberculosis diagnosis, various types of stem cell technology and the immunostimulant activity of oyster mushrooms. MUCSAT also offers product testing services for pharmaceutical firms.

if a project fails and takes full credit if it succeeds. As a result, integrative efforts are as difficult both within and among different institutions. This makes the initiation and completion of large projects very challenging. Weak monitoring and follow-up procedures within institutes exacerbate this problem, because there is no way to ensure that collaborative projects are pursued to completion, with the result that many projects remain unfinished.

There is also poor collaboration between industry and academia. Firms have traditionally found public research institutes to be ineffective in such relationships ${ }^{9}$. Thus, the transfer of technology, expertise and experience tend to be limited among regional actors. Although this is partly due to a legacy of mistrust, it is also due to the general inability of universities and public research institutes to sustain active links with industry and society at large.

Premature strengthening of national patent laws. Egypt was one of the founding signatories of the World Trade Organization (WTO, Geneva, Switzerland), joining in 1994. Now, there is widespread concern that the introduction in 2005 of patent standards compatible with the WTO TRIPS agreement, including a 20 -year patent term, will increase costs for the health sector, particularly for companies producing generics and biogenerics.

In response, the Egyptian government has opted to take full advantage of the transition period that is provided within the TRIPS. Egypt's new IP law permits the protection of microorganisms in addition to nonbiological and microbiological processes but denies protection for discoveries, diagnostics, plants, animals and biological processes for the production of plants and animals. It also prohibits the protection of organs, tissues, viable cells, DNA, genes, genomes and other biological matter to which no innovation has been applied. The new law also gave the Ministry of
Health firm control over all patents related to public health, making it responsible for strategic IP decisions in this sphere. Although these measures are aimed at balancing Egypt's trade obligations with the need to promote technological development and protect public health, major issues concerning the implications of the strength of the new IP rights regime for the local industry and health sector remain unresolved.

\section{Conclusions}

Egypt is in the preliminary stages of establishing a successful health biotechnology sector. In one expert's words, "Health biotechnology in Egypt reminds me of a baby that has a good start and is in good health for its stage of development, but it still needs to grow under proper care and guidance so that it is not swayed toward certain trends." Most local actors believe that the role and contribution of health biotechnology to public health and the overall economy will continue to increase in the future. The number of remaining weaknesses, however, tends to moderate expectations. If, as one respondent put it, "everything were to go as planned, we will maintain a respectable but modest position in the world."

Thus far, Egypt's health care biotechnology has mostly sprung from existing pharmaceutical and generics companies that have an interest in recombinant technologies in products for their business. By and large, these companies have drawn on contacts with the international community rather than local academic research. Three major lessons are apparent for encouraging innovative enterprises in an environment in which local interactions and collaborations are limited.

Focusing on meeting public health needs. Egypt's long-standing focus on meeting local public health needs is clearly present in its National Strategy, with its short-term plans for diagnostic kits for hepatitis $\mathrm{C}$, improving vaccine production and antibiotics manufacturing, as well as long-term plans to tackle diseases such as schistosomiasis and hepatitis $\mathrm{B}$ and $\mathrm{C}$ through vaccine developments.

A clear policy with manageable stages of implementation was important in getting the Egyptian health biotechnology sector off the ground, despite resource constraints. This process not only demonstrated government interest and commitment, but also engendered a sense of national pride and determination.

Gaining access to key actors. The ingenuity and determination of key individuals in the health biotechnology sector remains crucial in facing major challenges. The motivations and strengths of these people in different spheres of the national system of innovation tends to compensate, at least partially, for the missing or weak elements. According to one expert, "Individual effort here is very important, whether it is on the side of research or on the side of policy."

Armed with important connections, charisma, intelligence and power, key individuals in the sector can raise needed funds, perform good research and attract strong partners in the research and/or policy processes. The importance of key individuals in government, academia and industry was a recurrent theme identified by all the respondents in this case.

Taking advantage of international linkages. In contrast to its weak domestic linkages, Egyptian health biotechnology has

In contrast to its weak
domestic linkages, Egyptian
health biotechnology has
abundant and robust
international linkages.

abundant and robust international linkages. This is primarily because foreign education, training and technology remain the heart of the local health biotechnology sector. The result of this dependence on foreign education and training has led to the formation of a web of networks both with foreign experts and with those Egyptian scientists who choose to remain abroad.

Although education, training and support have been obtained in institutions mostly in the advanced industrialized countries, technology transfer has relied more on deals with advanced developing countries because of 


\section{COM MENTARY}

the cost effectiveness of these arrangements. Therefore, local actors draw extensively on diverse cooperative opportunities with counterparts from both the advanced industrial countries and the advanced developing countries. For instance, when El Nil Pharmaceutical established its biotechnology unit for the production of interferon $\alpha-1 b$, its management turned to the Chinese for infrastructure, the Germans for expertise and equipment, and the United States for technology and raw materials.

\section{ACKNOWLEDGMENTS}

Publication of this supplement was supported by the Bill and Melinda Gates Foundation (Seattle, WA), Genome Canada (Ottawa, Canada), McLaughlin Centre for Molecular Medicine (Toronto, Canada) and the Rockefeller Foundation (New York, NY). Special thanks to Archana Bhatt, Zoe Costa-von Aesch and James Renihan for patent analysis, Éric
Archambault, Frédéric Bertrand and Grégoire Côté at Science-Metrix (Montréal, Canada) for analysis of publication data and to the 25 Egyptian experts who gave their time and consideration to this study. The Canadian Program on Genomics and Global Health is primarily supported by Genome Canada through the Ontario Genomics Institute and by the Ontario Research and Development Challenge Fund. Funding partners are listed at http://www. geneticsethics.net. P.A.S. is supported by a Canadian Institutes of Health Research Distinguished Investigator award. A.S.D. is supported by the McLaughlin Centre for Molecular Medicine, University of Toronto. The authors declare that they have no competing interests.

1. Zahlan, A.B. in Scientific Communities in the Developing World (eds. Gaillard, J., Krishna, V.V. \& Waast, R.) 81-104 (Sage Publications, Thousand Oaks, CA, 1997).

2. El Nahhas, M. Al Ahram Online, 22-28 August 2002. http://weekly.ahram.org.eg/2002/600/eg5.htm

3. El Jesri, M. Egypt Today 25, 87-93 (2004).

4. World Health Organisation. The Role of Parenteral
Antischistosomal Therapy in the Spread of Hepatitis C Virus in Egypt (World Health Organisation, Geneva, 2000). http://www.who.int/csr/disease/hepatitis/ articlelancet/en/

5. El Awady, M.K. BioExchange 14 January 2003. http:// www.bioexchange.com/news/news page.cfm? id $=15892$

6. United Nations Conference on Trade and Development (UNCTAD). Investment Policy Review: Egypt (United Nations, Geneva, 1999).

7. Science-Metrix. Benchmarking of Genomics and Health Biotechnology in Seven Developing Countries, 19912004. Report Prepared for University of Toronto, Joint Centre for Bioethics (Science-Metrix, Quebec, 2004). Data derived from information (subset of Science Citation Index Expanded Database) Prepared by the nstitute for Scientific Information (ISI, Philadelphia, PA, USA). (C) Institute for Scientific Information. All rights reserved.

8. The Egyptian Ministry of Scientific Research (MOSR). Overview Report for Project on Improving Science and Technology Policy and Management in Egypt, A Project Conducted Under the Auspices of the Egyptian Ministry of Scientific Research and Funded by the World Bank, February 1997, WB 28836 (MOSR, Cairo, 1997).

9. Galal, E.E. World Development 11, 237-241 (1983). 